\title{
Relative Timing Between Kappa Opioid Receptor Activation and Cocaine Determines the Impact on Reward and Dopamine Release
}

\author{
Elena H Chartoff*, ', Shayla R Ebner², Angela Sparrow', David Potter', Phillip M Baker ${ }^{3}$, Michael E Ragozzino² \\ and Mitchell F Roitman ${ }^{2}$
}

'Department of Psychiatry, Harvard Medical School, McLean Hospital, Belmont, MA, USA; '2Department of Psychology, University of Illinois at Chicago, Chicago, IL, USA; ${ }^{3}$ Graduate Program in Neuroscience, University of Illinois at Chicago, Chicago, IL, USA

\begin{abstract}
Negative affective states can increase the rewarding value of drugs of abuse and promote drug taking. Chronic cocaine exposure increases levels of the neuropeptide dynorphin, an endogenous ligand at kappa opioid receptors (KOR) that suppresses dopamine release in the nucleus accumbens (NAc) and elicits negative affective states upon drug withdrawal. However, there is evidence that the effects of KOR activation on affective state are biphasic: immediate aversive effects are followed by delayed increases in reward. The impact of KORinduced affective states on reward-related effects of cocaine over time is not known. We hypothesize that the initial aversive effects of KOR activation increase, whereas the delayed rewarding effects decrease, the net effects of cocaine on reward and dopamine release. We treated rats with cocaine at various times ( 15 min to $48 \mathrm{~h}$ ) after administration of the selective KOR agonist salvinorin A (salvA). Using intracranial self-stimulation and fast scan cyclic voltammetry, we found that cocaine-induced increases in brain stimulation reward and evoked dopamine release in the NAc core were potentiated when cocaine was administered within I h of salvA, but attenuated when administered $24 \mathrm{~h}$ after salvA. Quantitative real-time PCR was used to show that KOR and prodynorphin mRNA levels were decreased in the NAc, whereas tyrosine hydroxylase and dopamine transporter mRNA levels and tissue dopamine content were increased in the ventral tegmental area $24 \mathrm{~h}$ post-salvA. These findings raise the possibility that KOR activation-as occurs upon withdrawal from chronic cocaine - modulates vulnerability to cocaine in a time-dependent manner.

Neuropsychopharmacology (2016) 4I, 989-1002; doi: I0.1038/npp.2015.226; published online 2 September 2015
\end{abstract}

\section{INTRODUCTION}

Baseline emotional states influence the rewarding and reinforcing impact of drugs of abuse (Koob and Le Moal, 2008). The interdependence of affect and addiction is exemplified in the high degree of comorbidity between drug addiction and mood disorders (Grant et al, 2004). Drugs of abuse produce profound changes in mood, which has been clearly articulated in the negative reinforcement model of drug addiction: chronic drug-induced negative affective states such as stress, depression, and anxiety enhance the valence (emotional value) of drug reward, thus promoting further drug taking (Koob and Le Moal, 2008). By extension, the opponent process theory of motivation posits that not only do rewarding stimuli trigger counter-adaptations that oppose reward, but aversive stimuli produce rewarding after-effects (Solomon and Corbit, 1974). Here, we explore

*Correspondence: Dr EH Chartoff, Department of Psychiatry, Harvard Medical School, McLean Hospital, MRC 218, I 15 Mill Street, Belmont, MA 02478, USA, Tel: + 617855 2022, Fax: + I 6178552023 , E-mail: echartoff@mclean.harvard.edu

Received 28 March 20I5; revised 12 July 20I5; accepted I4 July 20 I5; accepted article preview online 4 August 2015 the idea that the perceived rewarding impact of drugs of abuse may depend on the timing between a rewarding or aversive stimulus and drug administration.

The neuropeptide dynorphin, an endogenous ligand at kappa opioid receptors (KORs), is expressed within neural circuits that regulate affective state, including the mesocorticolimbic system (Knoll and Carlezon, 2010). KOR activation produces depressive-like and anxiogenic states (Bals-Kubik et al, 1993; Pliakas et al, 2001; Ebner et al, 2010), whereas KOR blockade or genetic deletion of KORs has antidepressant-like and anxiolytic effects (Pliakas et al, 2001; Newton et al, 2002; Mague et al, 2003; Knoll et al, 2007; Van't Veer and Carlezon, 2013). Evidence suggests that the neurobiological substrates for the depressive-like effects of KOR activation include suppression of dopamine release in the nucleus accumbens (NAc), a brain region important for reward processing (Spanagel et al, 1992; Carlezon et al, 2006; Ebner et al, 2010). One well-documented neuroadaptation to stress and drugs of abuse is an increase in the activity of KORs within the mesocorticolimbic system (Shippenberg et al, 2007; Knoll and Carlezon, 2010).

In drug-dependent humans and animals, dynorphin expression is coincident with the emergence of depressive-like states 
(Hurd and Herkenham, 1993; Shippenberg et al, 2007), suggesting that KOR activation contributes to negative reinforcement mechanisms driving continued drug taking and relapse (McLaughlin et al, 2006; Bruchas et al, 2010; Schindler et al, 2010). KOR agonists can increase the behavioral and neurochemical effects of psychostimulants, depending on the timing and context of KOR agonist exposure (Heidbreder et al, 1998; Fuentealba et al, 2006; Chartoff et al, 2008; Ehrich et al, 2014). Treatment of rhesus monkeys with the KOR agonist U-50,488 increases cocaine choice (Negus, 2004), suggesting a KOR-mediated increase in the relative reinforcing effects of cocaine. Stress-induced dynorphin release (McLaughlin et al, 2003) or pretreatment with KOR agonists (McLaughlin et al, 2006) can facilitate cocaine-induced place preferences, and activation of KORs can reinstate cocaine seeking (Redila and Chavkin, 2008). Conversely, KOR antagonists attenuate cocaine withdrawalinduced negative affective states (Chartoff et al, 2012), prevent stress-induced reinstatement of drug-seeking behavior (Beardsley et al, 2005; Aldrich et al, 2009), and attenuate drug self-administration under conditions of dependence (Walker and Koob, 2007; Wee et al, 2009).

The purpose of the present study was to test the hypothesis that the aversive effects of acute KOR activation engender neuroadaptations over time that subsequently increase reward function and weaken the rewarding valence of cocaine. We measured the effects of a cocaine challenge on brain stimulation reward using intracranial self-stimulation (ICSS) and-in separate rats-evoked dopamine release in the NAc core using fast scan cyclic voltammetry (FSCV) at various time points $(0-48 \mathrm{~h})$ after salvA. Importantly, a recent study used FSCV to demonstrate that an early effect of the KOR agonist U50,488 is a potentiation of stimulated dopamine release in the NAcs (Ehrich et al, 2014). ICSS is an operant paradigm that measures increases or decreases in reward sensitivity in real time. Treatments that induce rewarding states in humans decrease the frequency of stimulation required to maintain responding (thresholds), whereas treatments with depressive effects increase stimulation thresholds (Carlezon and Chartoff, 2007). Previously, we found that stimulation thresholds are increased immediately after an injection of the potent and highly selective KOR agonist salvinorin A (salvA) (Ebner et al, 2010), but decreased $24 \mathrm{~h}$ later (Potter et al, 2011). The underlying mechanisms for this rebound effect on reward function are not known, but may be triggered by inhibitory actions of KORs on dopamine release in the NAc (Di Chiara and Imperato, 1988; Ebner et al, 2010) and subsequent neuroadaptations in dopamine transmission. To explore potential cellular mechanisms underlying KOR-induced opponent processes, we measured KOR-related gene expression and dopamine tissue levels $24 \mathrm{~h}$ after a single salvA injection.

\section{MATERIALS AND METHODS}

\section{Animals}

A total of 236 male Sprague-Dawley rats (Charles River Laboratories) weighing approximately $350-400 \mathrm{~g}$ at the time of testing were used for these studies. Rats used for ICSS $(n=45)$ and for molecular studies $(n=130)$ were maintained at the McLean Hospital. Rats used for FSCV $(n=61)$ were maintained at the University of Illinois at Chicago (UIC). Rats used in ICSS and FSCV studies were individually housed so that head cap assemblies would not be damaged. Rats used in molecular experiments were housed in groups of four. Rats were maintained on ad libitum food and water on a $12 \mathrm{~h} / 12 \mathrm{~h}$ light/dark cycle, and all experiments were conducted during the light phase. All rats were treated according to the guidelines recommended by the Animal Care Committee at the University of Illinois at Chicago and Institutional Animal Care and Use Committee of McLean Hospital, in strict accordance with the National Institutes of Health's Guide for the Care and Use of Laboratory Animals (1996).

\section{Drugs}

SalvA was provided by Dr Cécile Béguin (McLean Hospital, Belmont, MA). The drug was extracted and purified according to established methods (Beguin et al, 2008). SalvA was dissolved in a vehicle of $75 \%$ dimethyl sulfoxide (DMSO) plus $25 \%$ distilled water (vehicle), and administered intraperitoneally (i.p.) at a dose of $2.0 \mathrm{mg} / \mathrm{kg} / \mathrm{d}$ in a volume of $1 \mathrm{ml} / \mathrm{kg}$, as in Chartoff et al (2008). Cocaine (Mallinckrodt) was dissolved in $0.9 \%$ saline and administered i.p. The dose range $(0.0-10.0 \mathrm{mg} / \mathrm{kg}$ in $1 \mathrm{ml} / \mathrm{kg})$ is based on a previous ICSS study (Tomasiewicz et al, 2008).

Intracranial self-stimulation. Rats were implanted with stainless steel monopolar electrodes $(0.25 \mathrm{~mm}$ diameter; Plastics One, Roanoke, VA) aimed at the medial forebrain bundle (MFB) at the level of the lateral hypothalamus ( $2.8 \mathrm{~mm}$ posterior to bregma, $+1.7 \mathrm{~mm}$ lateral to midline, and $7.8 \mathrm{~mm}$ below dura). After 1 week of recovery from surgery, rats were trained to respond for brain stimulation in standard experimental operant procedure chambers (Med Associates, St Albans, VT) using a continuous reinforcement schedule (FR1). Procedures have been described in detail elsewhere (Carlezon and Chartoff, 2007; Chartoff et al, 2012).

Rats were trained on a series of 15 descending stimulation frequencies $\left(141-28 \mathrm{~Hz}\right.$, in $0.05 \log _{10} \mathrm{~Hz}$ increments). Each series of frequencies comprised 1-min trials at each frequency. Each 1-min trial included a 5-s period during which non-contingent stimuli were given (1 per second) at the next available stimulation frequency, a 50 -s test period during which the number of responses was counted, and a 5-s period during which no stimulation was available. Each stimulation train was followed by a $500 \mathrm{~ms}$ time out. All responses were counted, regardless of whether they earned stimulation or occurred during a time out. After responding had been evaluated at each of the 15 frequencies, another series of identical frequencies was started. To characterize the functions relating response strength to reward magnitude (rate-frequency function), a least-squares line of best fit was plotted across the frequencies that sustained responding at $20,30,40,50$, and $60 \%$ of the maximum rate using customized analysis software. The stimulation frequency at which the line intersected the $\mathrm{X}$-axis (theta 0 ) was defined as the ICSS threshold (see Carlezon and Chartoff, 2007). Rats were trained for an average of 3-4 weeks until mean ICSS thresholds remained stable ( $\pm 10 \%$ for four consecutive days). 
a

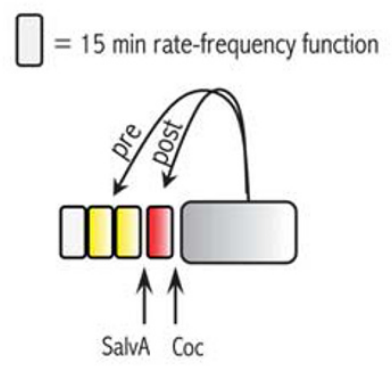

c

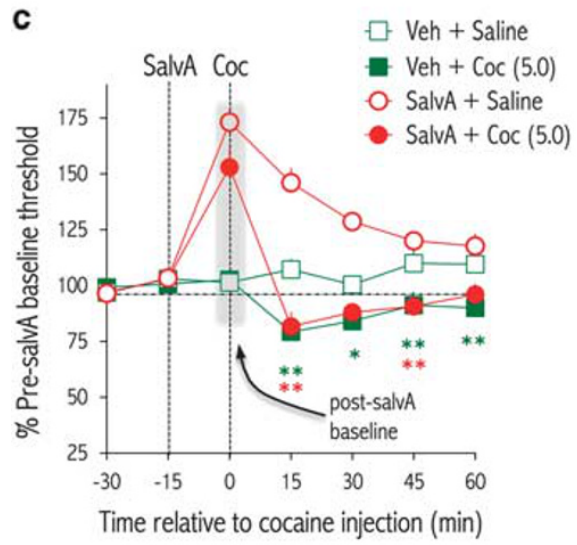

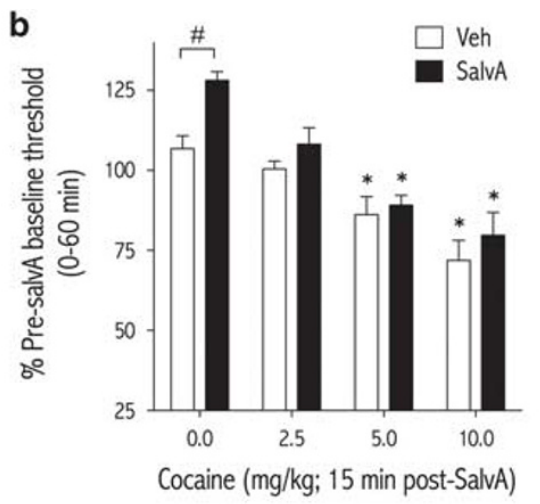

d

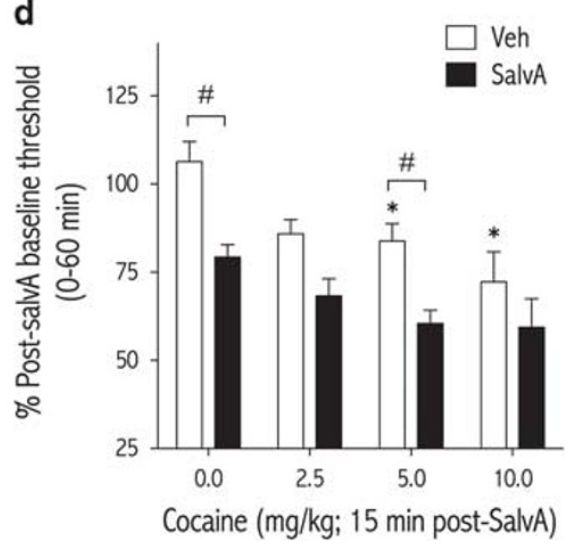

Figure I Baseline affective state impacts the net rewarding effects of cocaine in intracranial self-stimulation (ICSS). (a) To determine the rewarding impact of a cocaine challenge, cocaine-mediated decreases in stimulation thresholds can be compared with pre- or post-salvA baseline thresholds. Yellow boxes represent rate-frequency functions used to calculate pre-salvA baseline thresholds. Red boxes represent rate-frequency functions used to calculate post-salvA baseline thresholds. (b) Cocaine dose-dependently decreases \% pre-salvA baseline thresholds in rats treated with salvA (0.0, $2.0 \mathrm{mg} / \mathrm{kg}) \quad 15 \mathrm{~min}$ prior to cocaine $(0.0-10.0 \mathrm{mg} / \mathrm{kg})$. (c) Time course of changes in \% pre-salvA baseline thresholds in rats treated with salvA $(0.0,2.0 \mathrm{mg} / \mathrm{kg}) 15 \mathrm{~min}$ prior to cocaine $(0.0$, $5.0 \mathrm{mg} / \mathrm{kg}$ ). Cocaine has similar effects on ICSS thresholds in rats pretreated with salvA or vehicle. (d) Cocaine-mediated decreases in \% post-salvA baseline thresholds are greater in salvA- compared with veh-pretreated rats. $* P<0.05$, ${ }^{*} * P<0.0$ I compared with cocaine $(0.0 \mathrm{mg} / \mathrm{kg})$ of corresponding veh or salvA pretreatment; ${ }^{\#} P<0.05$ comparing groups under bars $(n=12)$. coc, cocaine; SalvA, salvinorin A; Veh, vehicle $(75 \%$ DMSO in water).

For drug testing, three rate-frequency functions $(3 \times 15$ min) were determined for each rat immediately before salvA (or 75\% DMSO vehicle) injection (see Figures 1a and 2b). The ICSS thresholds and maximum rates for the second and third functions were averaged and served as 'pre-salvA' baseline parameters. Each rat then received an i.p. injection of salvA $(2.0 \mathrm{mg} / \mathrm{kg})$ or vehicle followed by a delay of $15 \mathrm{~min}, 1,6,24$, or $48 \mathrm{~h}$ prior to a cocaine challenge. In order to obtain a 'post-salvA' (ie, pre-cocaine) baseline for each time point, rate-frequency curves were also generated just prior to cocaine delivery (see Figure $2 b$ ). Immediately after cocaine administration, rats were placed back in the ICSS boxes and four additional rate-frequency curves $(1 \mathrm{~h})$ were measured. For each salvA pretreatment time, a separate cohort of rats was used and all treatments were administered in random order in a within-subjects design. Drug treatment days were separated by two to three non-drug days in which the rats were exposed to six 15-min rate frequency functions to ensure that they had recovered from prior treatment and their ICSS thresholds remained within $10 \%$ of their original baseline values.
Fast scan cyclic voltammetry. Carbon fiber recording electrodes were lowered into the NAc core through surgically implanted guide cannulae $(1.3 \mathrm{~mm}$ anterior to bregma, $+1.5 \mathrm{~mm}$ lateral to midline, $2.5 \mathrm{~mm}$ ventral from skull surface) following established procedures (Ebner et al, 2010). A bipolar stimulating electrode $(0.20 \mathrm{~mm}$ diameter; Plastics One, Roanoke, VA) was positioned dorsal to the ventral tegmental area (VTA) $(5.2 \mathrm{~mm}$ posterior to bregma, $+1.0 \mathrm{~mm}$ lateral to midline, $7.0 \mathrm{~mm}$ ventral to skull surface) and lowered in $0.2 \mathrm{~mm}$ increments until electrically (60 pulses, $60 \mathrm{~Hz}, 120 \mu \mathrm{A}, 4 \mathrm{~ms} /$ phase) evoked dopamine release was detected via the carbon fiber electrode. After optimizing evoked dopamine release, the stimulating electrode was cemented and the carbon fiber electrode was removed and replaced with an obdurator (Ebner et al, 2010). Rats recovered when they reached pre-surgery body weight ( 2-5 days).

Recordings. FSCV measures extracellular concentrations of electroactive species including dopamine with subsecond temporal resolution and has been described in detail elsewhere (Fortin et al, 2015). Briefly, a fresh carbon fiber microelectrode is lowered into the NAc and held at $-400 \mathrm{mV}$ 
a

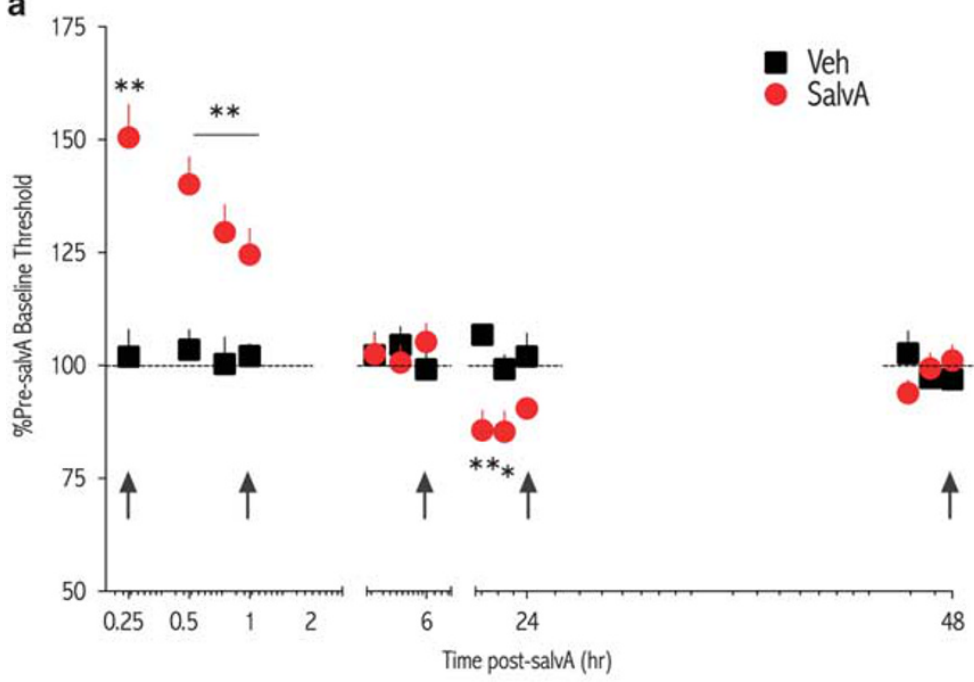

b

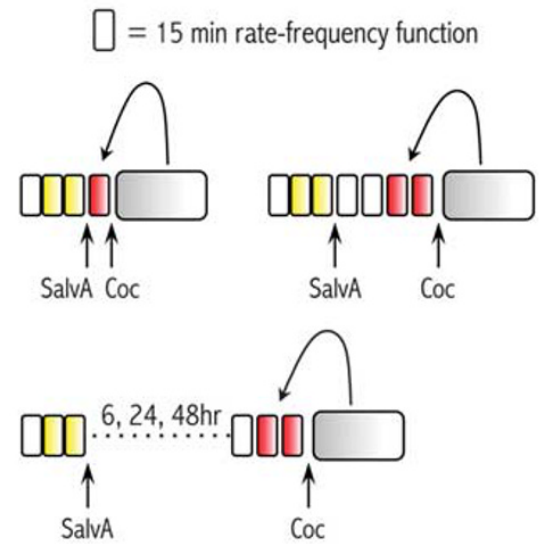

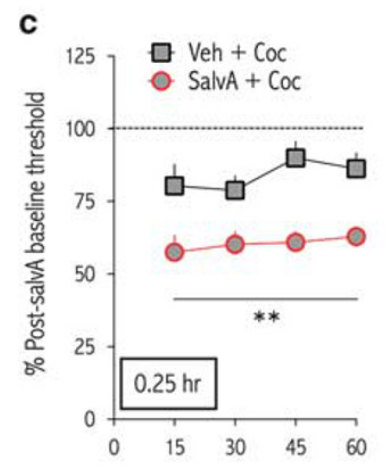
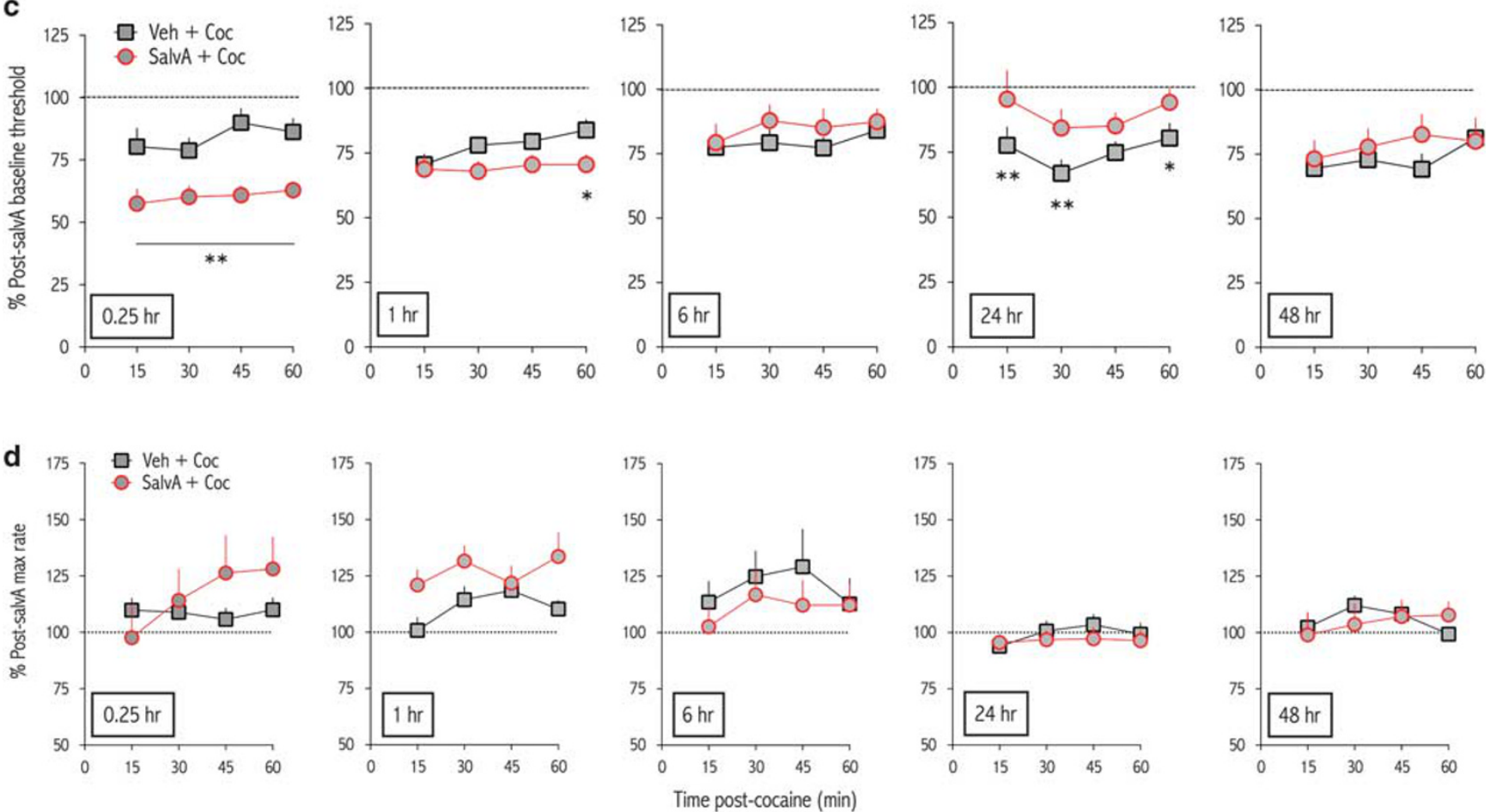

Figure 2 Relative timing of salvA pretreatment to cocaine challenge determines whether KOR activation increases or decreases the net rewarding effects of cocaine in ICSS. (a) Time course of salvA (0.0 or $2.0 \mathrm{mg} / \mathrm{kg}$ ) on ICSS thresholds. Data are reported as \% pre-salvA baseline thresholds \pm SEM and represent four cohorts of rats tested at different time points after salvA $(0.0,2.0 \mathrm{mg} / \mathrm{kg})$ injection: $0-0.25 \mathrm{~h}, 0.25-1.0 \mathrm{~h}, 5.25-6.0 \mathrm{~h}, 23.25-24.0 \mathrm{~h}, 47.25-48.0 \mathrm{~h}$.

(b) Diagram depicting how \% baseline stimulation thresholds and maximum rates of responding are calculated. Yellow boxes represent rate-frequency functions used to calculate pre-salvA baseline thresholds. Red boxes represent rate-frequency functions used to calculate post-salvA baseline thresholds. Stimulation thresholds collected after cocaine injection (grey boxes) are divided by post-salvA baseline thresholds and multiplied by 100 to obtain \% post-salvA baseline thresholds. (c) Time course of cocaine-induced changes in \% post-salvA baseline thresholds, or (d) max rates of responding, in rats treated with salvA $(0.0,2.0 \mathrm{mg} / \mathrm{kg}) 0.25, \mathrm{I}, 6,24$, or $48 \mathrm{~h}$ prior to cocaine $(0.0,5.0 \mathrm{mg} / \mathrm{kg})$. SalvA pretreatment times $(0.25, \mathrm{l}, 6,24$, and $48 \mathrm{~h})$ are indicated for each graph $\left(n=12,10,6,11\right.$, and 6, respectively). ${ }^{*} P<0.05$, ${ }^{*} * P<0.01$ comparing veh- and salvA-treated rats.

relative to the $\mathrm{Ag} / \mathrm{AgCl}$ reaction at the reference electrode. Periodically, the voltage is increased to $+1300 \mathrm{mV}$ and decreased to $-400 \mathrm{mV}$ in a triangular manner $(400 \mathrm{~V} / \mathrm{s})$. This triangle waveform is repeated at $10 \mathrm{~Hz}$. Chemical species that are electroactive within the voltage range will oxidize and reduce at various points along the triangle waveform and the resultant currents are measured at the surface of the electrode and recorded on a computer using software written in LabView (National Instruments, Schaumburg, IL) (Heien et al, 2004). The current arising from the double-layer capacitance and electroactivity of surface functional groups on the carbon fiber was removed by background subtraction. The background period $(1000 \mathrm{~ms})$ was obtained at $2.5 \mathrm{~s}$ before each stimulation of the VTA. Dopamine is electroactive within the applied voltage range, is identified by its oxidation (at $\sim 0.6 \mathrm{~V}$ ) and 
Table I qRT-PCR Primers

\begin{tabular}{|c|c|c|c|c|c|}
\hline Dyn & Pdyn & NM_019374 & CGCAAATACCCCAAGAGGAG & GCAGGAAGCCCCCATAGC & 109 \\
\hline KOR & Oprkl & NM_017167 & CTCCCAGTGCTTGCCTACTC & AGATGTTGGTTGCGGTCTTC & 240 \\
\hline Gai2 & Gnai2 & NM_03I035 & GATGATCGACAAGAACCTGCGGG & CAGGTTGCCCATGGCTTTGACG & 223 \\
\hline Grk3 & Adrbk2 & NM_0I2897 & TACGGAAGTACCCGCCACCCC & GTTTCGGCATTGACGGCGTCG & 211 \\
\hline $\mathrm{TH}$ & Th & NM_0I 2740 & TGAAGGCTTATGGTGCAGGGC & AATGGGCGCTGGATACGAGAGG & 211 \\
\hline$\beta$-actin & Nba & NM_03। I44 & AGGGAAATCGTGCGTGACAT & AAGGAAGGCTGGAAGAGAGC & 182 \\
\hline GTFIlb & $G t f 2 B$ & NM_03I04I & TGCGATAGCTTCTGCTTG TC & TCAGATCCACGCTCGTCTC & 155 \\
\hline GFAP & Gfap & NM_0I7009 & GCAGTGGCCACCAGTAACATGC & TCCTCCTGTTCGCGCATTTGCC & 215 \\
\hline
\end{tabular}

reduction (at $\sim-0.2 \mathrm{~V}$ vs $\mathrm{Ag} / \mathrm{AgCl}$ ) features, and is quantified by measuring its oxidative current, which is directly proportional to its concentration at the electrode surface (Fortin et al, 2015). Current is converted into concentration by means of calibrating the carbon fiber electrode after its use in a flow injection system with a known concentration of dopamine.

\section{Histology}

After completion of the FSCV experiments, rats were injected with a lethal dose of sodium pentobarbital $(100 \mathrm{mg} / \mathrm{kg})$. To verify the placement of the recording electrode in the NAc, an epoxy-insulated stainless steel microelectrode (A-M Systems) was lowered into the NAc to the depth where experimental recordings were made and an electrolytic lesion $(0.5 \mathrm{~mA}, 4 \mathrm{~s})$ was made. Following the lesion, rats were transcardially perfused with $0.9 \%$ saline followed by a $4 \%$ formalin solution. Coronal sections $(50 \mu \mathrm{m})$ through the NAc were made. The tissue was stained with cresyl violet and examined under a light microscope (VistaVision) for the location of the lesion. Placement of the recording electrode within the NAc was confirmed using Paxinos and Watson (Paxinos and Watson, 1996).

\section{High Performance Liquid Chromatography}

Rats were killed $15 \mathrm{~min}$ or $24 \mathrm{~h}$ after salvA $(0.0,2.0 \mathrm{mg} / \mathrm{kg})$ injection by rapid decapitation, and brains were rapidly removed, frozen, and stored at $-80^{\circ} \mathrm{C}$. Frozen brains were coronally sectioned on a cryostat (HM505E, Microm, Walldorf, Germany, $-20^{\circ} \mathrm{C}$ ) until reaching the NAc. Bilateral $1-\mathrm{mm}^{3}$ punches of the NAc core were made. Brains were sectioned further until reaching the VTA and bilateral $1-\mathrm{mm}^{3}$ punches were taken. Tissue punches were sonicated in $100 \mu \mathrm{l}$ of tissue buffer $(0.05 \mathrm{M}$ sodium phosphate $/ 0.03 \mathrm{M}$ citric acid, 25\% methanol (v/v), $\mathrm{pH} 2.5)$, and centrifuged twice at $22000 \mathrm{~g}$, as in Son et al (2011). Protein content of each sample was determined (Pierce BCA Protein Reagent Kit; Rockford, IL). Samples $(10 \mu \mathrm{l})$ were assayed for dopamine and its metabolite 3,4-dihydroxyphenylacetic acid (DOPAC) using high-pressure liquid chromatography with electrochemical detection. Samples were loaded on a microbore analytical column $5 \mu \mathrm{M}, \mathrm{C} 18,150 \times 1 \mathrm{~mm}$ UniJet SepStik (BASi, West Lafayette, IN) for separation. Quantities of dopamine and DOPAC were measured on a 3-mm glassy carbon-wired electrode operated at $+750 \mathrm{mV}$ vs an $\mathrm{Ag} / \mathrm{AgCl}$ reference electrode. The mobile phase consisted of $25 \mathrm{mM}$ $\mathrm{NaH}_{2} \mathrm{PO}_{4}, 50 \mathrm{mM}$ sodium citrate, $27 \mu \mathrm{M}$ EDTA, $10 \mathrm{mM}$ diethylamine $\mathrm{HCl}$, and $2.2 \mathrm{mM}$ 1-octanesulfonic acid sodium salt at a pH of 3.2 with $\mathrm{H}_{3} \mathrm{PO}_{4}$. Methanol $(30 \mathrm{ml})$ and dimethylacetamide $(22 \mathrm{ml})$ were added per 11 of Millipore water. After mixing, the solution was degassed for $20 \mathrm{~min}$. The mobile phase was delivered at a rate of $70 \mu \mathrm{l} / \mathrm{min}$ by a solvent delivery system (Shimadzu, Kyoto, Japan). Dopamine and DOPAC peaks were quantified by comparison with peak heights of four standard solutions each with a minimum $\mathrm{R}^{2}$ of 0.99 . The detection limit was $1 \mathrm{fmol}$.

\section{Quantitative Real-Time Reverse Transcriptase Polymerase Chain Reaction (qRT-PCR)}

Naïve male rats were treated with salvA $(2.0 \mathrm{mg} / \mathrm{kg})$ or vehicle (75\% DMSO) and returned to their home cages. Twenty-four hours later, rats were killed by decapitation and brains removed and immediately frozen in isopentane kept over dry ice. Bilateral tissue punches of the NAc and VTA were taken as described above for high performance liquid chromatography. RNA extraction, cDNA synthesis, and qRT-PCR were performed as described (Pravetoni et al, 2014). Briefly, RNA was extracted using PureLink RNA Mini Kit (Invitrogen). RNA quality and quantity were assessed using an RNA 6000 Nano Chip (Agilent, Santa Clara, CA) on an Agilent Bioanalyzer 2100. One microgram of total RNA was used to synthesize cDNA using iScript cDNA Synthesis Kit (Bio-Rad) in a ThermoHybaid iCycler (Thermo Scientific). Primers were designed using NCBI PrimerBLAST (http://www.ncbi.nlm.nih.gov/tools/primer-blast/) and purchased from Integrated DNA Technologies (Coralville, IA). See Table 1 for a list of primer sequences. Melt curve analysis and polyacrylamide gel electrophoresis confirmed the specificity of the primers.

A Q-PCR kit (iQ SybrGreen Supermix, Bio-Rad) was used. The reaction was carried out on a MyiQ Single Color RealTime PCR Detection System (Bio-Rad) in a volume of $20 \mu$, with $2 \mu \mathrm{l}$ of $3 \mathrm{mM}$ forward and reverse primers and $4 \mu \mathrm{l}$ cDNA sample diluted $1: 10$. PCR cycling conditions were $95^{\circ} \mathrm{C}$ for $5 \mathrm{~min} ; 40$ cycles at $94^{\circ} \mathrm{C}$ for $15 \mathrm{~s}, 60^{\circ} \mathrm{C}$ for $15 \mathrm{~s}$, $72^{\circ} \mathrm{C}$ for $15 \mathrm{~s}$. Data were collected at a read temperature of $84^{\circ} \mathrm{C}$ for $15 \mathrm{~s}$ based on the amplicon melt temperatures. For 
each brain region, standard dilution curves were generated for each primer set by serially diluting (1.00-, 0.25-, 0.0625-, and 0.0156 -fold) a master cDNA stock comprising an equal mix of cDNA from the two treatment groups. The $\log _{10}$ of the dilution values was plotted against the threshold cycle values for the standard curves. MyiQ Optical System Software (Bio-Rad) was used to analyze the data. Samples containing no cDNA template and samples from cDNA reactions containing no reverse transcriptase were run as controls for contamination and amplification of genomic DNA, respectively. Reported values were normalized to the average values of the internal standards $\beta$-actin, Gtf2b, and Gfap for each sample. Data are expressed as mean relative levels of [gene of interest/internal standard average] \pm SEM.

\section{Western Blot Analysis}

Naïve male rats were treated with salvA $(2.0 \mathrm{mg} / \mathrm{kg})$ or vehicle (75\% DMSO), returned to their home cages, and killed $24 \mathrm{~h}$ later by decapitation. Tissue punches of the NAc and VTA were taken as described above for qRT-PCR. SDS polyacrylamide gel electrophoresis and western blot analysis were done as described (Cone et al, 2013). Nonspecific binding sites on the polyvinylidene fluoride membrane protein immunoblots were blocked for $2 \mathrm{~h}$ at room temperature in blocking buffer (5\% nonfat dry milk in PBS and $0.1 \%$ Tween 20 (PBS-T)). Blots were then incubated in primary antibody in PBS-T overnight at $4{ }^{\circ} \mathrm{C}$. Primary antibodies used were: $1: 10000$ anti-TH (Millipore), $1: 2000$ anti-phospho Serine-31 tyrosine hydroxylase (TH) (Abcam), $1: 5000$ rabbit polyclonal anti-DAT (Millipore), and 1:20 000 rabbit polyclonal anti-actin (Sigma). Blots were washed $4 \times 5$ 5 min in PBS-T and then incubated in secondary antibody (1:5000 goat anti-rabbit (or anti-mouse) horseradish peroxidase-linked IgG (Vector Laboratories, Burlingame, $\mathrm{CA})$ ) for $2 \mathrm{~h}$ at room temperature. Blots were washed 45 5 min in PBS-T, followed by immunological detection using Chemiluminescence Reagent Plus (PerkinElmer Life Sciences). SeeBlue Plus 2 (Invitrogen) pre-stained standards were run for molecular weight estimation.

Protein immunoblots were analyzed using Kodak 1D Image Analysis software (Kodak, Rochester, NY). Relative optical densities were determined for each band of interest (TH and pTH at $60 \mathrm{kDa}, \mathrm{DAT}$ at 74 and $54 \mathrm{kDa}$, and $\beta$-actin at $43 \mathrm{kDa}$ ). To control for loading differences of protein, the optical density of each band was normalized with the corresponding optical density of $\beta$-actin. To allow for comparisons between blots, data were normalized to the vehicle-treated controls in each experiment. Data are expressed as the mean fold induction compared with vehicle control \pm SEM.

\section{Statistical Analysis}

The time course of drug effects on ICSS parameters (thresholds, maximum rates of responding) was analyzed using two-way (treatment $\times$ time) ANOVAs with repeated measures on both factors. The time course of drug effects on dopamine release was analyzed using two-way (treatment $x$ time) ANOVAs. Effects of salvA on cocaine dose response, gene and protein expression were analyzed using two-way (treatment $\times$ dose/gene) ANOVAs with repeated measures on cocaine dose, gene, and protein. The effect of salvA on tissue dopamine content was analyzed using two-way (treatment $\times$ time) ANOVAs. All significant effects and interactions were analyzed further using Bonferroni/Dunn's correction tests.

\section{RESULTS}

\section{Baseline Stimulation Threshold Determines the Magnitude of Cocaine-Mediated Increases in the Reinforcing Efficacy of ICSS}

Rats were treated with salvA $(0.0,2.0 \mathrm{mg} / \mathrm{kg})$ and ICSS behavior measured for $15 \mathrm{~min}$ (1 rate-frequency function). Rats were then treated with cocaine $(0.0,2.5,5.0,10.0 \mathrm{mg} / \mathrm{kg})$ and ICSS behavior measured for $1 \mathrm{~h}$. Post-cocaine changes in ICSS thresholds were compared with pre-salvA baseline thresholds (Figure 1a and b). The effect of a 15-min salvA pretreatment on cocaine-induced decreases in ICSS thresholds depended on salvA $\left(F_{1,11}=5.08, p<0.05\right)$ and cocaine dose $\left(F_{3,33}=38.47, p<0.0001\right)$ (Figure $\left.1 b\right)$. Bonferroni's post hoc analyses revealed that ICSS thresholds only differed between salvA and vehicle pretreatments at the $0.0 \mathrm{mg} / \mathrm{kg}$ cocaine dose. This is expected, as salvA on its own increases ICSS thresholds (Ebner et al, 2010). In both veh- and salvApretreated rats, cocaine at 5.0 and $10.0 \mathrm{mg} / \mathrm{kg}$ significantly decreased ICSS thresholds compared to veh+coc $(0.0 \mathrm{mg} / \mathrm{kg})$.

To more clearly visualize the effect of salvA pretreatment on cocaine-mediated decreases in ICSS thresholds, Figure 1c shows the time course of changes in percent pre-salvA baseline thresholds after salvA $(2.0 \mathrm{mg} / \mathrm{kg})$ and cocaine $(5.0 \mathrm{mg} / \mathrm{kg})$ treatments. The effect of salvA and cocaine on ICSS thresholds depends on a main effect of treatment $\left(F_{3,33}=27.63, p<0.0001\right)$, a main effect of time $\left(F_{6,66}=30.74\right.$, $p<0.0001)$, and an interaction between treatment and time $\left(F_{18,198}=15.84, p<0.0001\right)$. Post hoc tests demonstrate that cocaine significantly decreases ICSS thresholds compared with saline-treated rats, regardless of salvA pretreatment.

Given that salvA changes baseline affective states, we explored how post-salvA anhedonic baselines altered the rewarding effects of cocaine. We compared post-cocaine stimulation thresholds with post-salvA thresholds (Figure 1a), generating a 'delta' in thresholds that takes into account salvA-induced anhedonia. Using this method of analysis, the effects of salvA on cocaine reward depend on salvA pretreatment $\left(F_{1,11}=42.67, p<0.001\right)$ and cocaine dose $\left(F_{3,33}=5.98, p<0.01\right.$; Figure $\left.1 \mathrm{~d}\right)$. Post hoc tests show that cocaine dose-dependently decreases ICSS thresholds in vehicle-, but not salvA-, pretreated rats. Furthermore, the cocaine-induced decrease in thresholds from post-salvA baseline is larger in rats pretreated with salvA compared with vehicle-pretreated rats.

\section{Temporal, Biphasic Effects of salvA on ICSS}

Previously, we demonstrated that salvA has biphasic effects on brain stimulation reward. Initially, salvA produces a robust increase in ICSS thresholds that are followed, 24-h later, with a decrease in thresholds (Potter et al, 2011). We replicate and extend that finding here by examining the temporal effects of salvA on ICSS thresholds over the course of $48 \mathrm{~h}$ post-salvA injection. Separate groups of rats were 
used for each time segment post-salvA (15 min, 1, 6, 24, $48 \mathrm{~h}$ ). Figure 2 a shows a composite of post-salvA (or vehicle) thresholds relative to pre-salvA (or vehicle) thresholds for each time segment. Separate statistical analyses were carried out for each time segment. There were significant effects of treatment at the $15 \mathrm{~min}, 1$, and $24 \mathrm{~h}$ time points $(15 \mathrm{~min}$ : $t$-test, $\mathrm{t}=5.30, \quad p<0.01 ; 1 \mathrm{~h}: F_{1,8}=36.72, \quad p<0.01 ; 24 \mathrm{~h}$ : $\left.F_{1,10}=22.69, p<0.01\right)$. Post hoc tests showed that, compared with vehicle (75\% DMSO), salvA resulted in significantly increased ICSS thresholds for the first $60 \mathrm{~min}$ and significantly decreased ICSS thresholds $24 \mathrm{~h}$ after treatment. Thresholds were normalized by $48 \mathrm{~h}$.

\section{Effect of salvA on Cocaine-Mediated Decreases in ICSS Thresholds Depends on Time Interval between salvA and Cocaine Administration}

Next, we measured the magnitude of cocaine-induced decreases in ICSS thresholds $15 \mathrm{~min}, 1,6,24$, and $48 \mathrm{~h}$ after a single salvA $(2.0 \mathrm{mg} / \mathrm{kg})$ injection. For each time point, post-cocaine ICSS thresholds were compared with postsalvA (eg, pre-cocaine) baseline thresholds (see Figure 2b). Cocaine-induced changes in ICSS thresholds at $15 \mathrm{~min}, 1$, and $24 \mathrm{~h}$ depended on salvA pretreatment (Figure $2 \mathrm{c}$ ). When salvA was administered $15 \mathrm{~min}$ or $1 \mathrm{~h}$ prior to cocaine, the percent changes in thresholds from post-salvA baseline thresholds were significantly greater in rats pretreated with salvA compared with vehicle (Figure $2 \mathrm{c}$ : $0.25 \mathrm{~h}: F_{1,11}=18.02$, $p<0.001$; Figure 2c: $\left.1 \mathrm{~h}: F_{1,9}=5.64, p<0.05\right)$. In contrast, when salvA was administered $24 \mathrm{~h}$ prior to cocaine, the percent change in thresholds from post-salvA baseline thresholds was significantly less in rats pretreated with salvA compared with vehicle (Figure $2 \mathrm{c}$ : $24 \mathrm{~h} F_{1,10}=5.68, p<0.05$ ). Cocaine-induced decreases in ICSS thresholds were similar in rats treated $48 \mathrm{~h}$ earlier with salvA or vehicle. In contrast to effects on ICSS thresholds, which are a measure of reward sensitivity, salvA pretreatment did not affect maximum rates of responding in response to cocaine at any time point (Figure 2d). Time was a significant factor in the effects of cocaine on rates of responding in the 15 -min post-salvA group $\left(F_{3,33}=8.53, p<0.001\right.$; Figure $\left.2 \mathrm{~d}, 0.25 \mathrm{~h}\right)$.

\section{Effect of salvA on Cocaine-Mediated Increases in Evoked Dopamine Release Depends on Time Interval Between salvA and Cocaine Administration}

This study examined the temporal effects of acute salvA $(2.0 \mathrm{mg} / \mathrm{kg})$ on the magnitude of cocaine-potentiated dopamine release in the NAc core evoked by VTA stimulation. All data were normalized for each subject to the average of the baseline measurements (percent baseline) to control for differences in the initial magnitude of evoked dopamine release across rats. We have previously reported that salvA causes a rapid and robust suppression of stimulated dopamine release in the NAc core (Ebner et al, 2010). To start, we determined the effect of a 15-min salvA pretreatment on cocaine-potentiated dopamine release: rats were treated with salvA $(2.0 \mathrm{mg} / \mathrm{kg}) 15$-min prior to cocaine $(5.0 \mathrm{mg} / \mathrm{kg})$ (Figure $3 \mathrm{~b})$. Stimulated dopamine release was measured prior to any injection, and data collected in the 1 5-min prior to salvA were used as pre-salvA baseline (see schematic, Figure 3a). Stimulated dopamine release was measured for $15 \mathrm{~min}$ immediately after salvA injection, and these data were used as post-salvA baseline, and for $1 \mathrm{~h}$ immediately after cocaine injection. When the magnitude of evoked dopamine release is compared with pre-salvA baseline, there is a significant main effect of time $\left(F_{17,170}=33.85, \quad p<0.0001\right)$, but not treatment $\left(F_{1,10}=0.28, n s\right)$, and a significant interaction between treatment and time $\left(F_{17,170}=4.54, p<0.0001\right.$; Figure $\left.3 b\right)$. Post hoc analysis revealed that salvA significantly decreased dopamine levels compared with vehicle in the first $15 \mathrm{~min}$ post-salvA injection.

We next measured the magnitude of cocaine-induced increases in stimulated dopamine release $15 \mathrm{~min}, 1,6,24$, and $48 \mathrm{~h}$ after a single salvA $(2.0 \mathrm{mg} / \mathrm{kg})$ injection (Figure 3c). For each time point, the magnitude of post-cocaine dopamine was compared with post-salvA (eg, pre-cocaine) baseline levels. For the 15-min salvA pretreatment, the percent change from post-salvA baseline in cocaine-stimulated dopamine release depended on an interaction between treatment and time $\left(F_{11,55}=2.44\right.$, $p<0.05)$. Post hoc analysis showed that the potentiation of evoked dopamine release by cocaine from rats treated with salvA and cocaine was significantly greater than that from vehicle pre-treated rats at every time point except the first $5 \mathrm{~min}$ post-cocaine. For the 1 - and 24 -h salvA pretreatment groups, the percent change from post-salvA baseline in cocaine-stimulated dopamine release depended on time (1 h: $\quad F_{11,55}=12.39, \quad p<0.0001 ; \quad 24 \mathrm{~h}:: \quad F_{11,66}=11.50$, $p<0.0001)$. Post hoc analysis of the 1 -h salvA pretreatment group showed that cocaine-potentiated dopamine release from rats treated with salvA and cocaine was significantly greater than dopamine release from vehicle pre-treated rats for the first $10 \mathrm{~min}$ post-cocaine. In contrast, post hoc analysis of the 24-h salvA pretreatment group showed that cocaine-potentiated dopamine release from rats treated with salvA and cocaine was significantly blunted compared with dopamine release from vehicle pre-treated rats during the entire test session. Histological verification of electrode recording sites in the NAc core for each salvA pretreatment time are shown in Figure 4.

\section{Temporal Effects of salvA on Measures of Dopamine Synthesis}

Because salvA had temporally dependent and opposing effects on cocaine-potentiated reward and dopamine release, we used high performance liquid chromatography to measure the tissue content of dopamine and the dopamine metabolite DOPAC in the NAc and VTA 15 min or $24 \mathrm{~h}$ after a single salvA $(2.0 \mathrm{mg} / \mathrm{kg})$ or vehicle $(75 \% \mathrm{DMSO})$ injection in a separate group of rats. There was no significant effect of treatment or time on dopamine or DOPAC levels in the NAc (Figure $5 \mathrm{a}$ and $\mathrm{b}$ ). In the VTA, however, there was a significant effect of time on dopamine (Figure $5 \mathrm{c}$; $\left.F_{1,44}=5.94, p<0.05\right)$. At the 24-h time point, post hoc analysis showed a trend $(p=0.053)$ for dopamine content to be higher in the VTA of salvA-treated compared with vehicle-treated rats. Likewise, DOPAC levels in the VTA depended on treatment (Figure 5d; $F_{1,44}=4.10, p<0.05$ ), with post hoc tests showing that dopamine content was significantly higher in the VTA of salvA-treated compared with vehicle-treated rats $24 \mathrm{~h}$ after salvA treatment. 
a
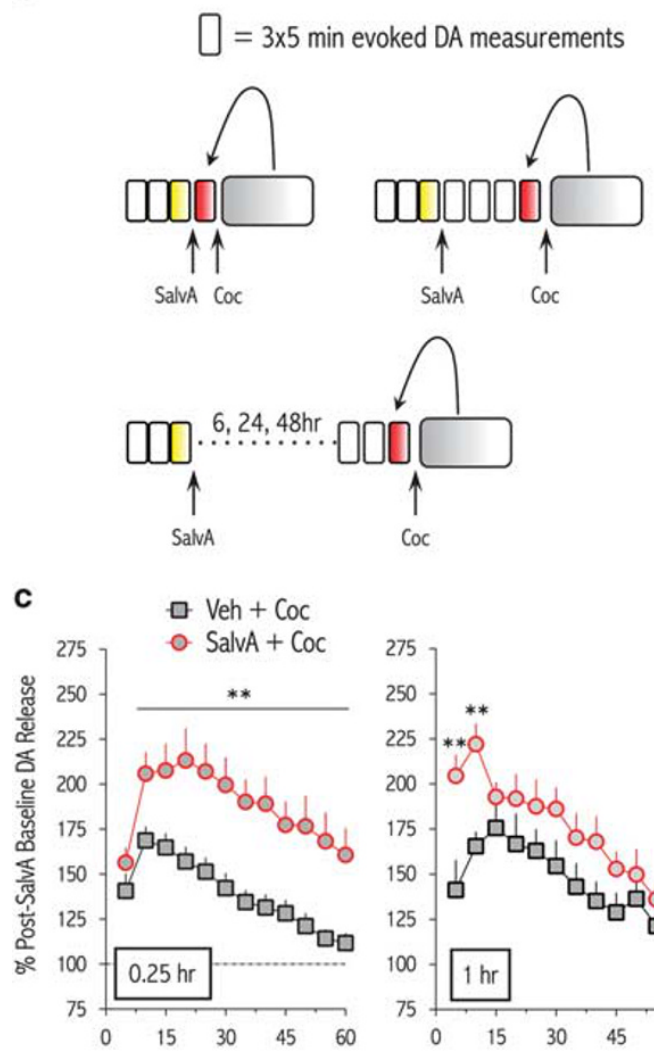

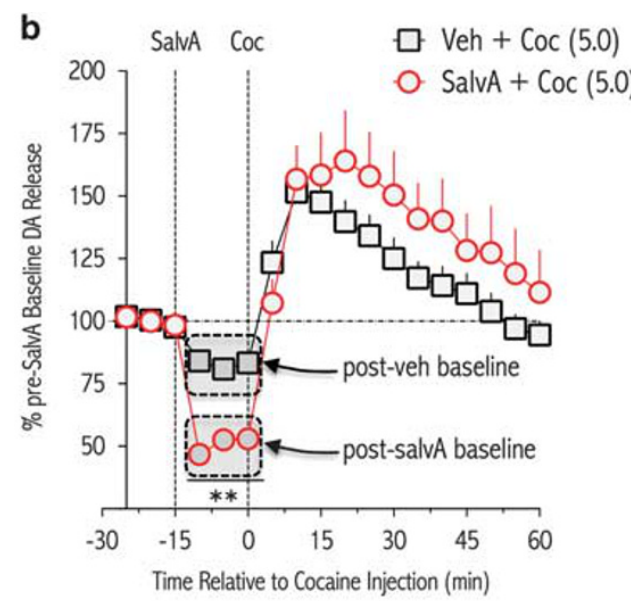

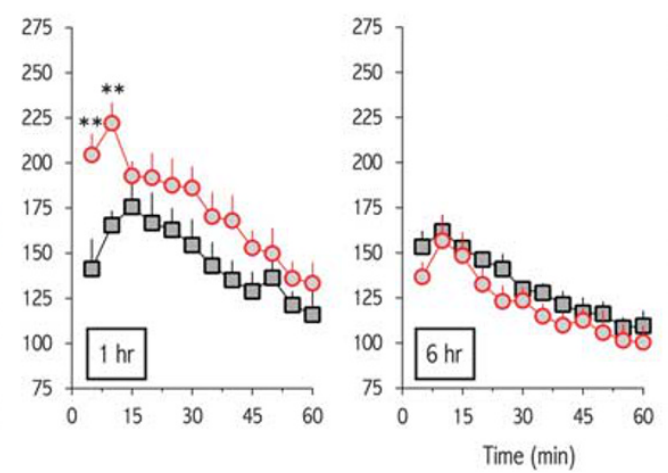
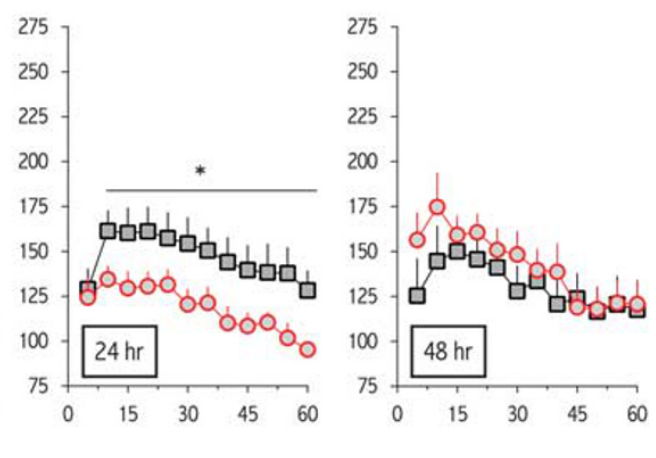

Figure 3 Relative timing of salvA pretreatment to cocaine challenge determines whether KOR activation increases or decreases cocaine-potentiated dopamine release in the nucleus accumbens (NAc) core measured with fast scan cyclic voltammetry (FSCV). (a) Diagram depicting how \% baseline dopamine release is calculated. Yellow boxes represent $3 \times 5$-min bins of VTA-stimulated dopamine release measurements taken just prior to salvA treatment (pre-salvA baseline). Red boxes represent $3 \times 5$-min bins of VTA-stimulated dopamine release measurements taken just prior to cocaine treatment (post-salvA baseline). (b) Time course of the effects of a cocaine $(5.0 \mathrm{mg} / \mathrm{kg}$ ) challenge administered $0.25 \mathrm{~h}$ after salvA (0.0, $2.0 \mathrm{mg} / \mathrm{kg})$ on \% pre-salvA baseline dopamine release. There is no significant difference in evoked dopamine release after a cocaine challenge between veh- and salvA-pretreated rats. (c) Time course of the effects of a cocaine $(5.0 \mathrm{mg} / \mathrm{kg})$ challenge administered $0.25,1,6,24$, or $48 \mathrm{~h}$ after salvA $(0.0,2.0 \mathrm{mg} / \mathrm{kg})$ on \% post-salvA baseline dopamine release. SalvA pretreatment times $(0.25,1,6,24$, and $48 \mathrm{~h})$ are indicated for each graph $(n=6-7)$. $* P<0.05$, $* * P<0.01$ comparing veh- and salvA-treated rats. VTA, ventral tegmental area.

\section{Effect of salvA on Expression of Dopamine-Related Genes in the NAcs and VTA $24 \mathrm{~h}$ Post Injection}

On the basis of the temporal effects of salvA on behavior and dopamine neurochemistry described above, we hypothesized that delayed (ie, $24 \mathrm{~h}$ ) effects of salvA would be associated with neuroplastic changes in dopamine-related gene expression in mesolimbic brain regions. We used qRT-PCR to determine whether a single salvA injection changes the expression levels of mRNAs encoding $\mathrm{TH}$ and the dopamine transporter (DAT). Tissue from the NAc and VTA was collected from rats $24 \mathrm{~h}$ after salvA $(2.0 \mathrm{mg} / \mathrm{kg})$ or vehicle (75\% DMSO) injection. There was a significant effect of treatment on the dopamine-related genes TH and DAT (Figure 6a; $\mathrm{F}_{(1,26)}=12.26, p<0.01$ ), with post hoc tests revealing that salvA significantly increased $\mathrm{TH}$ and DAT.

To determine whether salvA-mediated increases in $\mathrm{TH}$ and DAT mRNA resulted in increased protein expression, separate rats were treated with salvA $(2.0 \mathrm{mg} / \mathrm{kg})$ or vehicle (75\% DMSO), and tissue from the NAc and VTA was extracted $24 \mathrm{~h}$ later. Protein immunoblots were probed with antibodies specific for DAT, TH, and ERK-dependent phospho-Ser31 TH $\left(\mathrm{pTH}^{\mathrm{Ser} 31}\right)$. The DAT antibody recognizes both the non-reduced $74 \mathrm{kDa}$ and the reduced $54 \mathrm{kDa}$ forms of the transporter. KORs activate ERK (Bruchas and Chavkin, 2010; Potter et al, 2011), and $\mathrm{pTH}^{\text {Ser31 }}$ increases dopamine synthesis in the brain (Lindgren et al, 2002). In the VTA, protein expression depended on treatment (Figure 6b; $F_{1,50}=6.13, p<0.05$ ), with post hoc analysis showing a significant increase in pTH expression and a strong trend $(p=0.058)$ towards an increase in TH expression 24 -h after salvA compared with vehicle treatment. In the NAc, protein expression depended on an interaction between treatment and protein (Figure $6 c ; F_{2,51}=3.87, p<0.05$ ). Post hoc analysis showed that $24 \mathrm{~h}$ after salvA treatment, pTH levels were decreased, with no change in total TH levels. DAT protein exists in multiple states of glycosylation, which results in at least two DAT-specific bands (74 and $54 \mathrm{kDa}$ ) on our western blots. The largest molecular weight form of DAT is the most glycosylated and is considered to be the most mature form. Differences in expression levels of any 

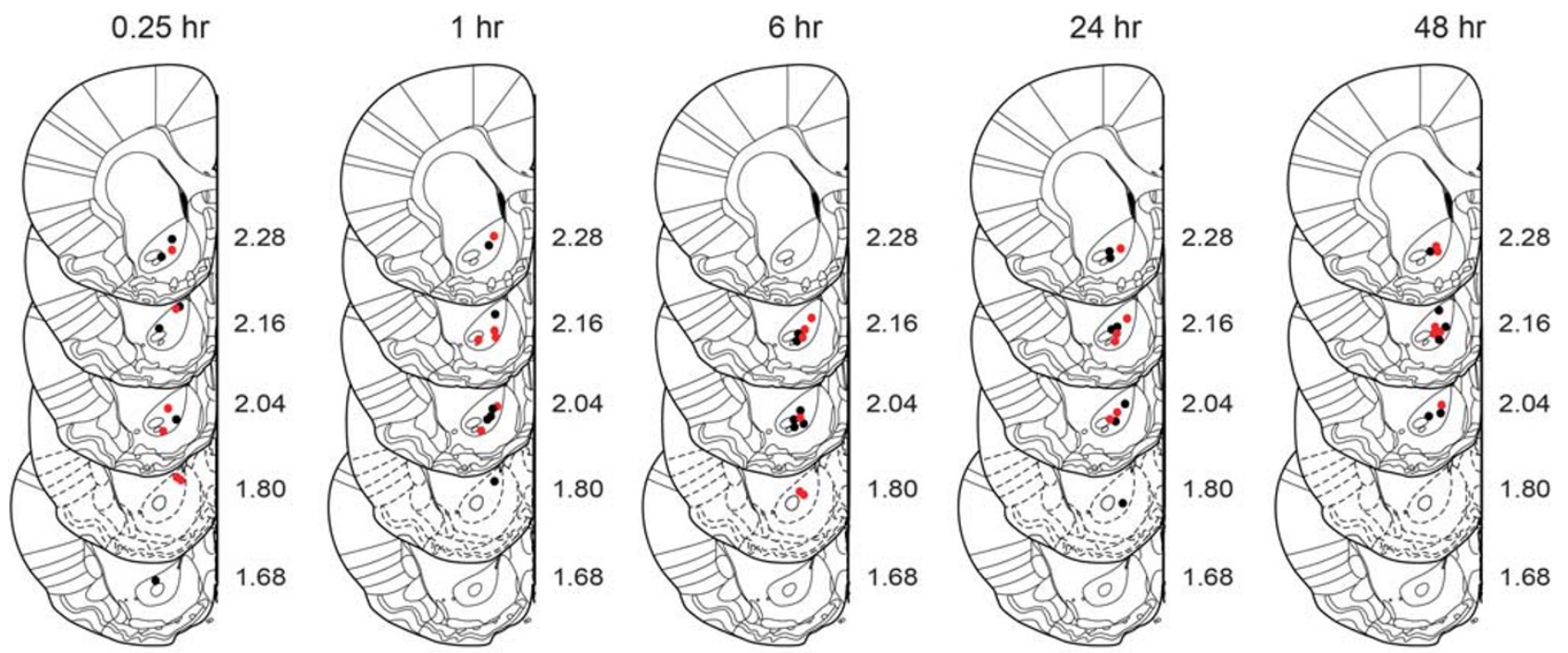

- Vehicle - Salvinorin A

Figure 4 Histological verification of recording sites. Electrolytic lesions confirmed that recording sites $(\bullet$, Vehicle- or $\bullet$, SalvA-treated rats) were within the nucleus accumbens core. The numbers to the right of individual sections indicate distance, in millimeters, anterior to bregma (Paxinos and Watson, 1996).

of the DAT isoforms could have functional effects on reuptake. However, we did not observe any differences in expression level at any DAT band. Data represented in Figure $6 \mathrm{~b}$ and $\mathrm{c}$ are from the $74 \mathrm{kDa}$ mature DAT band (see Figure $6 \mathrm{~d}$ and $\mathrm{e})$.

\section{Effect of salvA on Expression of KOR-Related Genes in the NAcs and VTA $24 \mathrm{~h}$ Post Injection}

We used qRT-PCR to measure the expression levels of a select number of genes whose protein products have a key role in transducing KOR signaling (dynorphin (Dyn), KOR, G-protein alpha inhibitory subunit 2 (Goi2), and G-protein receptor kinase 3 (Grk3)) and dopamine signaling (dopamine $\mathrm{D} 2$ receptor (D2R)). Messenger RNA levels in the NAc depended on treatment (Figure $7 \mathrm{a} ; F_{1,101}=25.29, p<0.0001$ ), with post hoc tests revealing that salvA significantly reduced Dyn, KOR, and G $\alpha$ i2. In the VTA, there was no effect of treatment on mRNA levels for KOR-related genes or D2Rs (Figure $7 \mathrm{~b} ; \mathrm{F}_{(3,95)}=1.078, n s$ ).

Given the salvA-mediated reductions in KOR signaling genes in the NAc, we hypothesized that the behavioral response to a challenge injection of salvA $24 \mathrm{~h}$ after the initial injection would be blunted (ie, tolerance). ICSS-trained rats were treated with salvA $(2.0 \mathrm{mg} / \mathrm{kg})$ and ICSS thresholds measured for $1 \mathrm{~h}$. Twenty-four hours later, rats were again treated with salvA $(2.0 \mathrm{mg} / \mathrm{kg})$ and ICSS thresholds measured for $1 \mathrm{~h}$. Changes in ICSS thresholds from pre-salvA (treatment 1) baseline were dependent on an interaction between treatment and time (Figure $7 \mathrm{c}$; $\left.F_{9,144}=2.42, p<0.05\right)$. Post hoc tests showed that salvA significantly increased ICSS thresholds on both days 1 and 2 . Although the effect of salvA on ICSS thresholds on day 2 was consistently less than the effect on day 1 , the difference was not significant, suggesting a lack of overt tolerance to the threshold-increasing effects of salvA at a single 24-h inter-injection interval.

\section{DISCUSSION}

The present study addressed the question of whether KOR activation has biphasic effects on the magnitude of cocaine reward in rats. Consistent with our hypothesis and previous findings (McLaughlin et al, 2006; Schindler et al, 2010; Ehrich et al, 2014), we found that the immediate $(0.25-1 \mathrm{~h})$ dysphoric effect of the KOR agonist salvA coincides with a net increase in sensitivity to cocaine reward. In contrast, a delayed $(24 \mathrm{~h})$ effect of salvA is a rebound increase in basal hedonic state that coincides with a net decrease in sensitivity to cocaine reward. These biphasic effects of KOR activation on sensitivity to cocaine reward temporally map onto the effects of KOR activation on cocaine-modulated dopamine release in the NAc core. An immediate effect of salvA is a decrease in dopamine release evoked by VTA stimulation that coincides with a net increase in cocaine-potentiated dopamine release, consistent with Ehrich et al (2014). In contrast, a delayed effect of salvA is an increase in measures of dopamine signaling that coincides with a net decrease in cocaine-potentiated dopamine release. These delayed behavioral and electrochemical effects of KOR activation that are evident $24 \mathrm{~h}$ post-salvA are correlated with decreased expression of genes encoding KOR, prodynorphin, and the inhibitory Goi2 G-protein subunit in the NAc and increased expression of genes encoding TH and DAT in the VTA. Taken together with our observation of increased TH protein expression and dopamine tissue content in the VTA, these data raise the possibility that the initial KOR-mediated decreases in NAc dopamine release trigger compensatory adaptations in both KOR- and dopamine-related signaling pathways that result in a delayed emergence of enhanced baseline dopaminergic activity and reward sensitivity.

The rewarding properties of cocaine are not fixed, but are modulated by external and internal stimuli including baseline affective state (Koob and Le Moal, 2008; Schindler et al, 2010). Although KOR activation can oppose the acute 


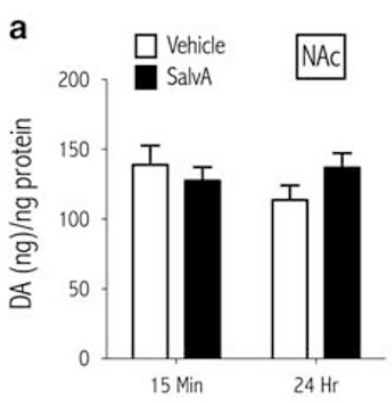

Pretreatment Time

C

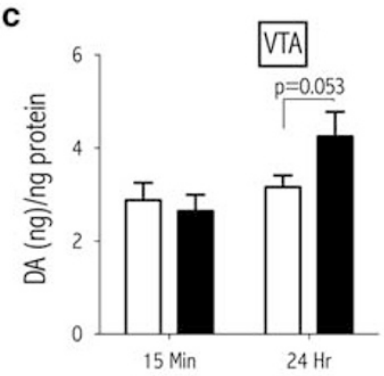

Pretreatment Time b

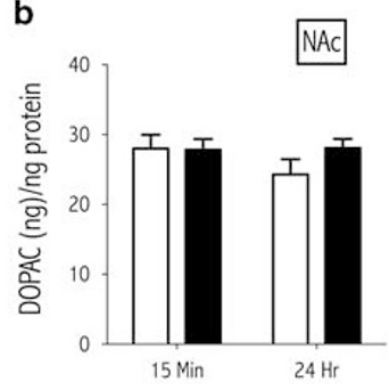

Pretreatment Time

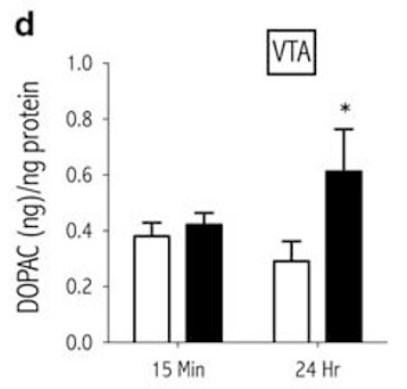

Pretreatment Time
Figure 5 Tissue content of dopamine and its metabolite DOPAC in the nucleus accumbens (NAc) and ventral tegmental area (VTA) using high performance liquid chromatography (HPLC). There was no difference in tissue dopamine (a) or DOPAC (b) levels in the NAc $15 \mathrm{~min}$ or $24 \mathrm{~h}$ after salvA $(2.0 \mathrm{mg} / \mathrm{kg})$ treatment. Twenty-four hours after salvA treatment, there was a trend towards an increase in dopamine (c), and a significant increase in DOPAC (d) levels in the VTA $(n=12), * P<0.05$ comparing veh- and salvA-treated rats.

intoxicating effects of cocaine (Negus et al, 1997; Schenk et al, 1999; Tomasiewicz et al, 2008), accumulating evidence suggests that the behavioral consequence of KOR activation most relevant to addiction is negative reinforcement. In this process, response-contingent cessation of an aversive state increases the probability of a subsequent response. In other words, KOR activation promotes drug taking as a means to ameliorate stress- or drug-withdrawal-induced negative affective states. We-and others-argue that the rewarding valence of cocaine is defined by the magnitude of change (delta) from pre-cocaine to post-cocaine hedonic state (Bruchas et al, 2010; Schindler et al, 2010; Ehrich et al, 2014). Although ICSS does not directly model addiction, our findings are consistent with those showing that KOR activation can increase motivation to seek cocaine and precipitate relapse (Negus, 2004; Beardsley et al, 2005; Redila and Chavkin, 2008; Graziane et al, 2013). KOR-triggered rebound positive affective states are short-lived, as ICSS thresholds return to pre-salvA baseline levels by $48 \mathrm{~h}$. This is consistent with brain homeostatic regulatory mechanisms, which are reactionary responses to acute stimuli. Conceptually, this idea is the flip of that proposed for hedonic processes associated with intake of drugs of abuse (Koob and Le Moal, 2008).

Using FSCV, we conducted parallel studies of the temporal effects of salvA on cocaine-induced potentiation of evoked dopamine release in the NAc core. We focused on the core because salvA-mediated inhibition of dopamine release in the NAc core is greater than in the shell (Ebner et al, 2010).
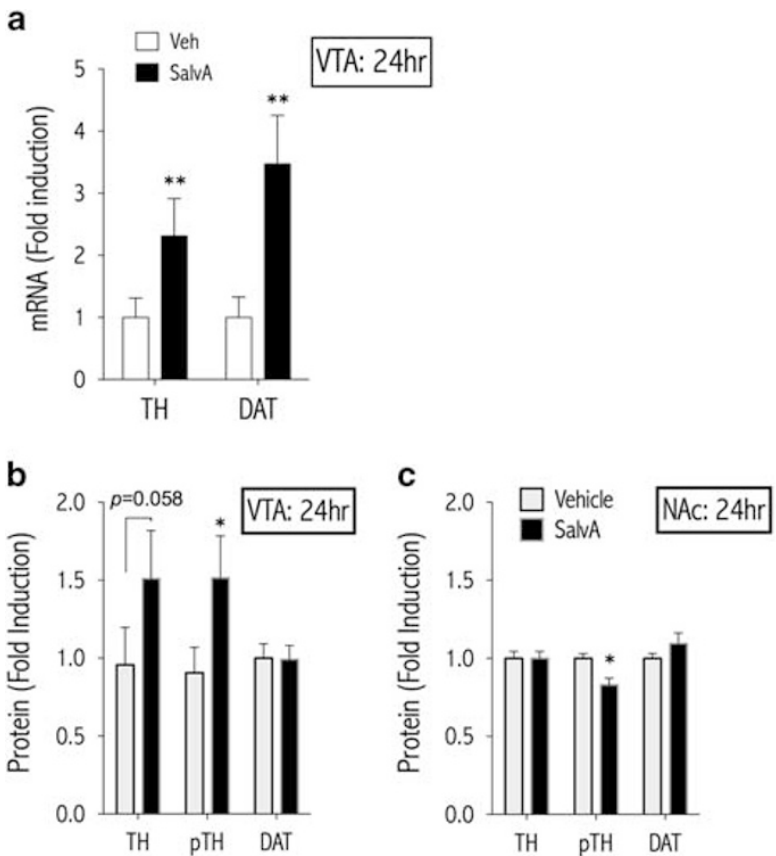

d
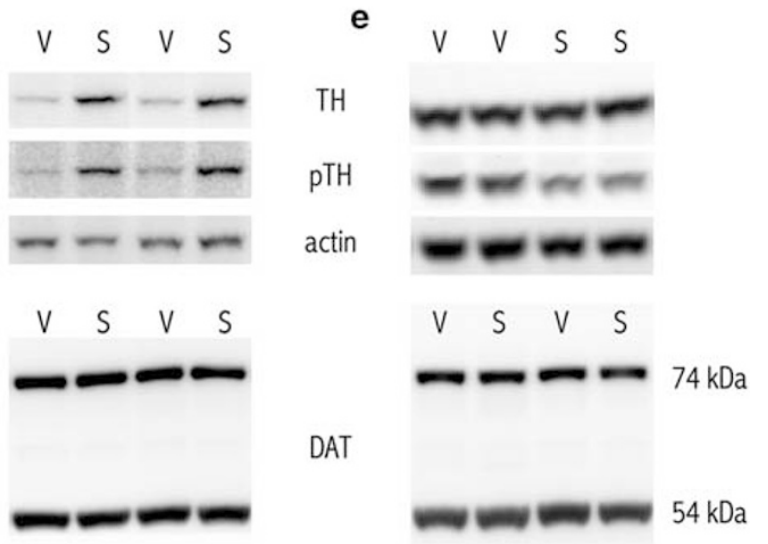

Figure 6 Gene and protein expression analysis using western immunoblotting in the nucleus accumbens (NAc) and ventral tegmental area (VTA) of rats $24 \mathrm{~h}$ after salvA $(0.0,2.0 \mathrm{mg} / \mathrm{kg})$. (a) TH and DAT mRNA levels are increased in the VTA $24 \mathrm{~h}$ after salvA $(0.0,2.0 \mathrm{mg} / \mathrm{kg})$. (b) There is a trend for levels of total $\mathrm{TH}(p=0.058)$ to be increased, and $\mathrm{pTH}^{\text {Ser3l }}$ levels are significantly increased, in VTA tissue punches from salvA-treated compared with veh-treated rats $(n=8-12)$. (c) Levels of $\mathrm{TH}$ phosphorylated at the extracellular signal regulated kinase-sensitive serine residue 3 I (pTHSer3 I) are reduced in NAc tissue punches from salvA-treated compared with veh-treated rats $(n=8-12)$. (d, e) Representative western immunoblot images. $* P<0.05$, $* * P<0.0$ I comparing veh- and salvA-treated rats. DAT, dopamine transporter; $\mathrm{S}$, salvA; $\mathrm{TH}$, tyrosine hydroxylase; $\mathrm{V}$, vehicle.

Importantly, our goal in this study was to isolate the effects of KOR activation on dopamine release dynamics. Therefore, we chose to evoke dopamine release by directly stimulating the VTA, rather than the MFB, which we used for our ICSS studies. It has previously been demonstrated that stimulation of the VTA and MFB with similar trains evokes similar electrochemical responses in the NAc as measured by FSCV (Cheer et al, 2004; Cheer et al, 2006), and KOR agonists produce similar reductions in dopamine release in the NAC 

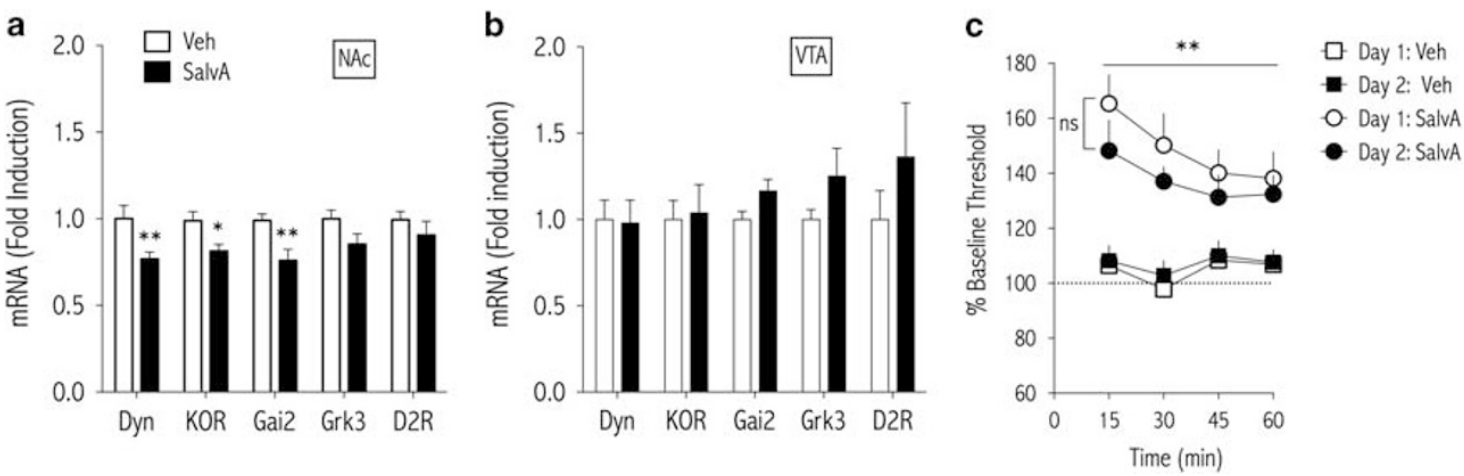

Figure 7 Gene expression analysis using qRT-PCR in the nucleus accumbens (NAc) and ventral tegmental area (VTA) of rats $24 \mathrm{~h}$ after salvA $\left(0.0,2.0 \mathrm{mg} / \mathrm{kg}\right.$ ). Levels of Dyn, KOR, and $\mathrm{G} \alpha_{i 2}$, Grk3, and D2R mRNA are measured in (a) NAc and (b) VTA tissue punches from salvA-treated compared with veh-treated rats (NAc: $n=10-12$; VTA: $n=6-9)$. (c) Rats are treated with salvA (0.0 or $2.0 \mathrm{mg} / \mathrm{kg}$ ) on day I and again $24 \mathrm{~h}$ later on day 2 to test for tolerance. ICSS thresholds are measured immediately after each salvA injection. SalvA significantly increases ICSS thresholds on both days I and 2, with no significant difference in responses between the days $(n=13)$. $* P<0.05$, **P $<0.0$ I comparing veh- and salvA-treated rats. Dyn, dynorphin; Grk3, G-protein receptor kinase 3; KOR, kappa opioid receptor.

when either the MFB or the VTA is used to stimulate dopamine neurons (Ehrich et al, 2014). However, the effects on dopamine neurons are indirect with MFB stimulation, which comprises over 50 fiber systems (Carlezon and Chartoff, 2007). Our finding that the net increase in dopamine release produced by a cocaine challenge is potentiated immediately after salvA compliments a recent study in mice showing that $1 \mathrm{~h}$ after administration of the KOR agonist U50,488, cocaine-potentiated NAc dopamine release evoked by either pedunculopontine tegmental nucleus or VTA stimulation is increased (Ehrich et al, 2014). These findings are also consistent with previous work showing that KOR agonists can increase stimulated dopamine release in the striatum (Heidbreder et al, 1998; Fuentealba et al, 2006). Conditions that reduce stimulated dopamine release create a system with low dopamine 'noise' (Weiss et al, 1992; Volkow et al, 1997). Subsequent stimuli that trigger phasic dopamine release, which is associated with initiating goal-directed behaviors (Phillips et al, 2003; Roitman et al, 2004), enhance the signal to noise of phasic dopamine signaling and promote drug seeking.

Our finding that the net increase in cocaine-stimulated dopamine release is attenuated $24 \mathrm{~h}$ after salvA suggests neuroplasticity within mesolimbic circuits. Indeed, the expression of TH mRNA and protein, as well as a form of ERK-activated (phosphorylated) TH (pTH) is elevated in the VTA $24 \mathrm{~h}$ post-salvA. Furthermore, there is a significant increase in tissue levels of the dopamine metabolite DOPAC in the VTA as well as a strong trend for increased dopamine. Taken together, these results suggest that a compensatory neuroadaptation to KOR-mediated inhibition of dopamine release is upregulation of dopamine synthesis. Interestingly, salvA-induced TH mRNA in the VTA is associated with increased TH protein in the VTA but not the NAc, an afferent target of VTA dopamine neurons. There is precedent for this, as $\mathrm{TH}$ protein levels are increased in the VTA, but not the NAc, following 1 day of withdrawal from cocaine self-administration (Lu et al, 2003). Levels of pTH in the NAc, which most likely originate from dopaminergic terminals, are decreased $24 \mathrm{~h}$ post-salvA. Together with unchanged dopamine content in the NAc, these data suggest that the delayed effects of KOR activation on dopamine synthesis occur in VTA dopaminergic neurons that project to regions other than the NAc (eg, prefrontal cortex). Although DAT mRNA levels are increased in the VTA $24 \mathrm{~h}$ after salvA, protein levels remain constant, which is consistent with the slow rate of de novo DAT protein synthesis (Kimmel et al, 2000).

An alternative, but not mutually exclusive, explanation for the delayed effect of salvA on cocaine-stimulated dopamine release is that KOR activation suppresses KOR signaling itself, which could indirectly promote dopamine release through loss of inhibitory input. Indeed, we found that prodynorphin, KOR, and Gai2 mRNA levels are decreased in the NAc $24 \mathrm{~h}$ after salvA injection. Although not physiologically verified at this point, these findings are consistent with a large body of literature describing compensatory changes in neuropeptide and G-protein expression and function in response to manipulations of dopamine signaling within the mesolimbic system. Dopamine depletion results in decreased dynorphin expression (Gerfen, 2000), whereas the dopamine-releasing drug amphetamine stimulates transcription of dynorphin (Cole et al, 1995) and increases dynorphin release, which subsequently desensitizes KORs (Xia et al, 2008). The mechanism underlying KOR agonist-mediated KOR desensitization is not fully understood, but may involve the downregulation of G-proteins such as Goi2. We did not observe salvA-mediated changes in KOR-related gene expression in the VTA, suggesting that KORs to this area are unchanged, whereas dynorphin levels in NAc efferents to the VTA are decreased. The effect of decreased KOR expression on intrinsic NAc neurons is not well understood, in part because the phenotype of KOR-expressing medium spiny neurons is not known (Svingos et al, 2001). Consistent with desensitization of KOR signaling-regardless of mechanism-we found that the threshold-increasing effects of a second salvA injection were consistently (but not significantly) lower than those of the first salvA injection.

In subtle contrast to our findings, Ehrich et al (2014) showed that a 15-min pretreatment with the KOR agonist U50,488 attenuates, whereas a 1-h pretreatment potentiates, cocaine-induced conditioned place preferences (see also 
McLaughlin et al (2006) and NAc dopamine release evoked by pedunculopontine tegmental nucleus stimulation. U50,488-mediated conditioned place aversions are observed at $15 \mathrm{~min}$, but not $1 \mathrm{~h}$, which seems to contradict the hypothesis that dysphoria enhances sensitivity to cocaine reward. However, we have shown previously that U50,488 produces immediate elevations in ICSS thresholds that last for at least $2 \mathrm{~h}$ (Russell et al, 2014). Although salvA and U50,488 have unique pharmacological properties (Liu-Chen, 2004), it is most likely that the observed differences in behavioral results between the current study and that of Ehrich et al (2014) are due to the different aspects of rewardrelated behavior measured by place conditioning and ICSS (Carlezon, 2003; Carlezon and Chartoff, 2007). Unlike ICSS, place conditioning requires associative learning and memory between drug effect and context, which raises the possibility that an immediate effect of KOR activation is suppression of learning and memory processes. This is broadly consistent with the finding that KOR agonists inhibit long-term potentiation in the hippocampus (Terman et al, 1994) and produce deficits in attention (Nemeth et al, 2010).

The dynamic effects of KOR activation on affective state and neural circuits described here highlight the complexity of developing treatments for drug addiction and may help answer a long-standing divide in the literature. On one hand, numerous studies support the idea that KOR activation has drug-opposite effects and conclude that KOR agonists might have utility in combatting addiction (Mello and Negus, 2000; Shippenberg, 2009; Kivell et al, 2014). On the other hand, a growing body of evidence supports the idea that KOR activation has drug-withdrawal-like effects that promote addictive behavior and conclude that KOR antagonists should be effective in combatting addiction (Walker and Koob, 2007; Aldrich and McLaughlin, 2009; Bruchas et al, 2010; Jackson et al, 2010). This divide is well illustrated by a study in which the KOR antagonist JDTic blocks stressinduced reinstatement of cocaine seeking but potentiates cocaine-induced reinstatement (Beardsley et al, 2005). One possible resolution is the use of KOR partial agonists (Beguin et al, 2009), which would be expected to mute both the intoxicating effects and the withdrawal-induced depressivelike effects of drugs of abuse (Carlezon et al, 2009).

\section{FUNDING AND DISCLOSURE}

The authors declare no conflict of interest.

\section{ACKNOWLEDGMENTS}

This work was supported by National Institutes of Health grants DA023094 (to EHC), DA025634 (to MFR), and P50 HD055751 (to MER).

\section{REFERENCES}

Aldrich JV, McLaughlin JP (2009). Peptide kappa opioid receptor ligands: Potential for drug development. AAPS 11: 312-322.

Aldrich JV, Patkar KA, McLaughlin JP (2009). Zyklophin, a systemically active selective kappa opioid receptor peptide antagonist with short duration of action. Proc Natl Acad Sci U S A 106: 18396-18401.
Bals-Kubik R, Ableitner A, Herz A, Shippenberg TS (1993). Neuroanatomical sites mediating the motivational effects of opioids as mapped by the conditioned place preference paradigm in rats. J Pharmacol Exp Ther 264: 489-495.

Beardsley PM, Howard JL, Shelton KL, Carroll FI (2005). Differential effects of the novel kappa opioid receptor antagonist, jdtic, on reinstatement of cocaine-seeking induced by footshock stressors vs cocaine primes and its antidepressant-like effects in rats. Psychopharmacology (Berl) 183: 118-126.

Beguin C, Duncan KK, Munro TA, Ho DM, Xu W, Liu-Chen LY et al (2009). Modification of the furan ring of salvinorin a: Identification of a selective partial agonist at the kappa opioid receptor. Bioorg Med Chem 17: 1370-1380.

Beguin C, Potter DN, Dinieri JA, Munro TA, Richards MR, Paine TA et al (2008). N-methylacetamide analog of salvinorin a: A highly potent and selective kappa-opioid receptor agonist with oral efficacy. J Pharmacol Exp Ther 324: 188-195.

Bruchas MR, Chavkin C (2010). Kinase cascades and liganddirected signaling at the kappa opioid receptor. Psychopharmacology (Berl) 210: 137-147.

Bruchas MR, Land BB, Chavkin C (2010). The dynorphin/kappa opioid system as a modulator of stress-induced and pro-addictive behaviors. Brain Res 1314: 44-55.

Carlezon WA Jr (2003). Place conditioning to study drug reward and aversion. Methods Mol Med 84: 243-249.

Carlezon WA Jr, Beguin C, Dinieri JA, Baumann $\mathrm{MH}$, Richards MR, Todtenkopf MS et al (2006). Depressive-like effects of the kappa-opioid receptor agonist salvinorin a on behavior and neurochemistry in rats. J Pharmacol Exp Ther 316: 440-447.

Carlezon WA Jr, Chartoff EH (2007). Intracranial self-stimulation (icss) in rodents to study the neurobiology of motivation. Nat Protoc 2: 2987-2995.

Carlezon WAJ, BËguin C, Knoll AT, Cohen BM (2009). Kappa-opioid ligands in the study and treatment of mood disorders. Pharmacol Ther 123: 334-343.

Chartoff E, Sawyer A, Rachlin A, Potter D, Pliakas A, Carlezon WA (2012). Blockade of kappa opioid receptors attenuates the development of depressive-like behaviors induced by cocaine withdrawal in rats. Neuropharmacology 62: 167-176.

Chartoff EH, Potter D, Damez-Werno D, Cohen BM, Carlezon WA Jr (2008). Exposure to the selective kappa-opioid receptor agonist salvinorin a modulates the behavioral and molecular effects of cocaine in rats. Neuropsychopharmacology 33: 2676-2687.

Cheer JF, Wassum KM, Heien MLAV, Phillips PEM, Wightman RM (2004). Cannabinoids enhance subsecond dopamine release in the nucleus accumbens of awake rats. $J$ Neurosci 24: 4393-4400.

Cheer JF, Wassum KM, Wightman MR (2006). Cannabinoid modulation of electrically evoked ph and oxygen transients in the nucleus accumbens of awake rats. $J$ Neurochem 97: 1145-1154.

Cole RL, Konradi C, Douglass J, Hyman SE (1995). Neuronal adaptation to amphetamine and dopamine: Molecular mechanisms of prodynorphin gene regulation in rat striatum. Neuron 14: 813-823.

Cone JJ, Chartoff EH, Potter DN, Ebner SR, Roitman MF (2013). Prolonged high fat diet reduces dopamine reuptake without altering dat gene expression. PLoS One 8: e58251.

Di Chiara G, Imperato A (1988). Opposite effects of mu and kappa opiate agonists on dopamine release in the nucleus accumbens and in the dorsal caudate of freely moving rats. J Pharmacol Exp Ther 244: 1067-1080.

Ebner SR, Roitman MF, Potter DN, Rachlin AB, Chartoff EH (2010). Depressive-like effects of the kappa opioid receptor agonist salvinorin a are associated with decreased phasic 
dopamine release in the nucleus accumbens. Psychopharmacology (Berl) 210: 241-252.

Ehrich JM, Phillips PE, Chavkin C (2014). Kappa opioid receptor activation potentiates the cocaine-induced increase in evoked dopamine release recorded in vivo in the mouse nucleus accumbens. Neuropsychopharmacology 39: 3036-3048.

Fortin SM, Cone JJ, Ng-Evans S, McCutcheon JE, Roitman MF (2015). Sampling phasic dopamine signaling with fast-scan cyclic voltammetry in awake, behaving rats. Curr Protoc Neurosci 70: $72521-272520$.

Fuentealba JA, Gysling K, Magendzo K, Andres ME (2006). Repeated administration of the selective kappa-opioid receptor agonist u-69593 increases stimulated dopamine extracellular levels in the rat nucleus accumbens. J Neurosci Res 84: 450-459.

Gerfen CR (2000). Molecular effects of dopamine on striatalprojection pathways. Trends Neurosci 23: S64-S70.

Grant BF, Stinson FS, Dawson DA, Chou SP, Dufour MC, Compton W et al (2004). Prevalence and co-occurrence of substance use disorders and independent mood and anxiety disorders: Results from the national epidemiologic survey on alcohol and related conditions. Arch Gen Psychiatry 61: 807-816.

Graziane NM, Polter AM, Briand LA, Pierce RC, Kauer JA (2013). Kappa opioid receptors regulate stress-induced cocaine seeking and synaptic plasticity. Neuron 77: 942-954.

Heidbreder CA, Schenk S, Partridge B, Shippenberg TS (1998). Increased responsiveness of mesolimbic and mesostriatal dopamine neurons to cocaine following repeated administration of a selective kappa-opioid receptor agonist. Synapse 30: $255-262$.

Heien ML, Johnson MA, Wightman RM (2004). Resolving neurotransmitters detected by fast-scan cyclic voltammetry. Anal Chem 76: 5697-5704.

Hurd YL, Herkenham M (1993). Molecular alterations in the neostriatum of human cocaine addicts. Synapse 13: 357-369.

Jackson K, Carroll FI, Negus S, Damaj M (2010). Effect of the selective kappa-opioid receptor antagonist jdtic on nicotine antinociception, reward, and withdrawal in the mouse. Psychopharmacology (Berl) 210: 285-294.

Kimmel HL, Carroll FI, Kuhar MJ (2000). Dopamine transporter synthesis and degradation rate in rat striatum and nucleus accumbens using rti-76. Neuropharmacology 39: 578-585.

Kivell BM, Ewald AW, Prisinzano TE (2014). Salvinorin a analogs and other kappa-opioid receptor compounds as treatments for cocaine abuse. Adv Pharmacol 69: 481-511.

Knoll AT, Carlezon WA Jr (2010). Dynorphin, stress, and depression. Brain Res 1314: 56-73.

Knoll AT, Meloni EG, Thomas JB, Carroll FI, Carlezon WA Jr (2007). Anxiolytic-like effects of kappa-opioid receptor antagonists in models of unlearned and learned fear in rats. J Pharmacol Exp Ther 323: 838-845.

Koob GF, Le Moal M (2008). Addiction and the brain antireward system. Annu Rev Psychol 59: 29-53.

Lindgren N, Goiny M, Herrera-Marschitz M, Haycock JW, Hökfelt T, Fisone G (2002). Activation of extracellular signalregulated kinases 1 and 2 by depolarization stimulates tyrosine hydroxylase phosphorylation and dopamine synthesis in rat brain. Eur J Neurosci 15: 769-773.

Liu-Chen LY (2004). Agonist-induced regulation and trafficking of kappa opioid receptors. Life Sci 75: 511-536.

Lu L, Grimm JW, Shaham Y, Hope BT (2003). Molecular neuroadaptations in the accumbens and ventral tegmental area during the first 90 days of forced abstinence from cocaine selfadministration in rats. J Neurochem 85: 1604-1613.

Mague SD, Pliakas AM, Todtenkopf MS, Tomasiewicz HC, Zhang Y, Stevens WC Jr et al (2003). Antidepressant-like effects of kappa-opioid receptor antagonists in the forced swim test in rats. J Pharmacol Exp Ther 305: 323-330.
McLaughlin JP, Land BB, Li S, Pintar JE, Chavkin C (2006). Prior activation of kappa opioid receptors by u50,488 mimics repeated forced swim stress to potentiate cocaine place preference conditioning. Neuropsychopharmacology 31: 787-794.

McLaughlin JP, Marton-Popovici M, Chavkin C (2003). Kappa opioid receptor antagonism and prodynorphin gene disruption block stress-induced behavioral responses. $J$ Neurosci 23: 5674-5683.

Mello NK, Negus SS (2000). Interactions between kappa opioid agonists and cocaine: preclinical studies. Annals NY Acad Sci 909: 104-132.

Negus SS (2004). Effects of the kappa opioid agonist u50,488 and the kappa opioid antagonist nor-binaltorphimine on choice between cocaine and food in rhesus monkeys. Psychopharmacology (Berl) 176: 204-213.

Negus SS, Mello NK, Portoghese PS, Lin CE (1997). Effects of kappa opioids on cocaine self-administration by rhesus monkeys. J Pharmacol Exp Ther 282: 44-55.

Nemeth CL, Paine TA, Rittiner JE, Beguin C, Carroll FI, Roth BL et al (2010). Role of kappa-opioid receptors in the effects of salvinorin a and ketamine on attention in rats. Psychopharmacology (Berl) 210: 263-274.

Newton SS, Thome J, Wallace TL, Shirayama Y, Schlesinger L, Sakai $\mathrm{N}$ et al (2002). Inhibition of camp response elementbinding protein or dynorphin in the nucleus accumbens produces an antidepressant-like effect. J Neurosci 22: 10883-10890.

Paxinos G, Watson C (1996). The Rat Brain in Stereotaxic Coordinates. Academic Press.

Phillips PEM, Stuber GD, Heien ML, Wightman RM, Carelli RM (2003). Subsecond dopamine release promotes cocaine seeking. Nature 422: 614-618.

Pliakas AM, Carlson RR, Neve RL, Konradi C, Nestler EJ, Carlezon WA Jr (2001). Altered responsiveness to cocaine and increased immobility in the forced swim test associated with elevated camp response element-binding protein expression in nucleus accumbens. J Neurosci 21: 7397-7403.

Potter DN, Damez-Werno D, Carlezon WA Jr, Cohen BM, Chartoff EH (2011). Repeated exposure to the kappa-opioid receptor agonist salvinorin a modulates extracellular signalregulated kinase and reward sensitivity. Biol Psychiatry 70: 744-753.

Pravetoni M, Pentel PR, Potter DN, Chartoff EH, Tally L, LeSage MG (2014). Effects of an oxycodone conjugate vaccine on oxycodone self-administration and oxycodone-induced brain gene expression in rats. PLoS One 9: e101807.

Redila V, Chavkin C (2008). Stress-induced reinstatement of cocaine seeking is mediated by the kappa opioid system. Psychopharmacology (Berl) 200: 59-70.

Roitman MF, Stuber GD, Phillips PE, Wightman RM, Carelli RM (2004). Dopamine operates as a subsecond modulator of food seeking. J Neurosci 24: 1265-1271.

Russell SE, Rachlin AB, Smith KL, Muschamp J, Berry L, Zhao Z et al (2014). Sex differences in sensitivity to the depressive-like effects of the kappa opioid receptor agonist u-50488 in rats. Biol Psychiatry 176: 213-222.

Schenk S, Partridge B, Shippenberg TS (1999). U69593, a kappaopioid agonist, decreases cocaine self-administration and decreases cocaine-produced drug-seeking. Psychopharmacology (Berl) 144: 339-346.

Schindler AG, Li S, Chavkin C (2010). Behavioral stress may increase the rewarding valence of cocaine-associated cues through a dynorphin/kappa-opioid receptor-mediated mechanism without affecting associative learning or memory retrieval mechanisms. Neuropsychopharmacology 35: 1932-1942.

Shippenberg TS (2009). The dynorphin/kappa opioid receptor system: A new target for the treatment of addiction and affective disorders[quest]. Neuropsychopharmacology 34: 247-247. 
Shippenberg TS, Zapata A, Chefer VI (2007). Dynorphin and the pathophysiology of drug addiction. Pharmacol Ther 116: 306-321.

Solomon RL, Corbit JD (1974). An opponent-process theory of motivation: I. Temporal dynamics of affect. Psychol Rev 81: $119-145$.

Son JH, Latimer C, Keefe KA (2011). Impaired formation of stimulus-response, but not action-outcome, associations in rats with methamphetamine-induced neurotoxicity. Neuropsychopharmacology 36: 2441-2451.

Spanagel R, Herz A, Shippenberg TS (1992). Opposing tonically active endogenous opioid systems modulate the mesolimbic dopaminergic pathway. Proc Natl Acad Sci U S A 89: 2046-2050.

Svingos AL, Chavkin C, Colago EE, Pickel VM (2001). Major coexpression of kappa-opioid receptors and the dopamine transporter in nucleus accumbens axonal profiles. Synapse 42: 185-192.

Terman GW, Wagner JJ, Chavkin C (1994). Kappa opioids inhibit induction of long-term potentiation in the dentate gyrus of the guinea pig hippocampus. I Neurosci 14: 4740-4747.

Tomasiewicz HC, Todtenkopf MS, Chartoff EH, Cohen BM, Carlezon WA Jr. (2008). The kappa-opioid agonist u69,593 blocks cocaine-induced enhancement of brain stimulation reward. Biol Psychiatry 64: 982-988.

Van't Veer A, Carlezon WA Jr (2013). Role of kappa-opioid receptors in stress and anxiety-related behavior. Psychopharmacology (Berl) 229: 435-452.

Volkow ND, Wang GJ, Fowler JS, Logan J, Gatley SJ, Hitzemann R et al (1997). Decreased striatal dopaminergic responsiveness in detoxified cocaine-dependent subjects. Nature 386: 830-833.

Walker BM, Koob GF (2007). Pharmacological evidence for a motivational role of [kappa]-opioid systems in ethanol dependence. Neuropsychopharmacology 33: 643-652.

Wee S, Orio L, Ghirmai S, Cashman J, Koob G (2009). Inhibition of kappa opioid receptors attenuated increased cocaine intake in rats with extended access to cocaine. Psychopharmacology (Berl) 205: 565-575.

Weiss F, Paulus MP, Lorang MT, Koob GF (1992). Increases in extracellular dopamine in the nucleus accumbens by cocaine are inversely related to basal levels: Effects of acute and repeated administration. J Neurosci 12: 4372-4380.

Xia YF, He L, Whistler JL, Hjelmstad GO (2008). Acute amphetamine exposure selectively desensitizes kappa-opioid receptors in the nucleus accumbens. Neuropsychopharmacology 33: 892-900. 